\title{
Considerações éticas na investigação com vítimas de violência e de crime
}

\author{
Sónia Caridade ${ }^{1}$ \\ ${ }^{1}$ Faculdade de Ciências Humanas e Sociais, Universidade Fernando Pessoa (UFP); Centro de Investigação em \\ Ciências Sociais e do Comportamento (FPB2S) da UFP
}

\begin{abstract}
Resumo: A investigação vitimológica é fundamental para o desenvolvimento de políticas que possam promover a segurança e o equilíbrio emocional das vítimas. Na produção deste conhecimento científico colocam-se inúmeros preceitos éticos que devem ser devidamente salvaguardados sob pena de se poder promover uma revitimação. A experienciação de uma situação de vitimação poderá ter efeitos muito nefastos, podendo interferir com a capacidade das vítimas para decidir a sua participação numa investigação. Tendo por base as evidências em torno do impacto da violência e do crime nas suas vítimas, pretende-se ao longo deste artigo elencar algumas das principais questões éticas subjacentes à produção científica neste domínio, identificando alguns dos cuidados e recomendações a implementar. A observância deste conjunto de guidelines é fundamental para a realização de uma investigação de qualidade e para mitigar eventuais danos que a mesma possa causar nos seus participantes.
\end{abstract}

Palavras-chave: Investigação; Vítimas; Violência; Crime; Ética.

Ethical issues in research with victims of violence and crime: Research in the field of victimology is important to develop policies that can promote safety and emotional stability of the victims. Nevertheless, in the production of this knowledge arise numerous ethical issues that must be considered. The nonrespect for them can promote a revictimization. The victimization experiences can result in very adverse effects and may interfere with the ability of the victims to decide to participate in a research. Based on the evidence around the impact of violence and crime on its victims, we pretend in this article to list some of the major ethical issues underlying the scientific production in this area, identifying the main care and recommendations to be implemented in this regard. Taking into account this set of guidelines is essential for carrying out a quality research and to mitigate any damage that it can cause in their participants.

Keywords: Research; Victims; Violence; Crime; Ethic.

A emergência da vitimologia no final dos anos 40, enquanto área de investigação, impulsionou na comunidade científica, especialmente a partir dos anos 70, um crescente interesse em investigar os diferentes fenómenos de vitimação, e os quais surgem retratados em diferentes obras internacionais (e.g., Doerner \& Lab, 2012; Karmen, 2012) e nacionais de referência na área da vitimologia (e.g., Alberto, 2006; Caridade, 2011; Machado, 2010a, b; Machado \& Gonçalves, 2002; Neves \& Fávero, 2011; Sani, 2011 a, b). De entre os diversos fenómenos de vitimação individual que mais têm suscitado interesse, destacam-se a violência íntima, os maus tratos a menores e o abuso sexual. A maioria dos estudos vitimológicos, influenciados em grande medida pelo feminismo e pela psicologia clínica, têm como preocupação principal perceber e identificar o impacto emocional e as sequelas que estes fenómenos acarretam para as suas vítimas (Machado, 2010a) (diretas ou indiretas), ou mesmo para a sociedade em geral. Não obstante, será de registar também outras de linhas de estudo, que apoiadas nos inquéritos de vitimação, procuraram conhecer e descrever a extensão dos diversos fenómenos de vitimação (Machado, 2010a).

A exposição, direta ou indireta, a um qualquer fenómeno de vitimação poderá acarretar diversos constrangimentos a diferentes níveis (individuais, familiares, sociais) para as vítimas, familiares, profissionais que prestam apoio ou mesmo até para a própria comunidade. Tais constrangimentos potenciam, não raras vezes, uma maior vulnerabilidade nas vítimas, o que poderá repercutir-se na sua capacidade de decisão para participar, voluntária e livremente, numa investigação. Tal tem inclusive motivado o desenvolvimento de vários estudos que procuram analisar a reação dos participantes ao processo investigativo (e.g., Fontes, 1998).

Não obstante, a produção de investigação vitimológica é fundamental para o desenvolvimento de políticas e respostas sociais que possam promover a segurança e o equilíbrio emocional das vítimas.

${ }^{1}$ Endereço para correspondência: Faculdade de Ciências Humanas e Sociais da Universidade Fernando Pessoa, Praça 9 de Abril, 349 , 4249004 Porto. E-mail: soniac@ufp.edu.pt 
Neste sentido, com este trabalho de revisão da literatura pretendemos identificar e discutir as principais questões éticas envolvidas na investigação com vítimas adultas de violência, dando particular destaque ao fenómeno de vitimação na intimidade (contexto onde se insurgem muitos desafios éticos que exigem cuidados redobrados ao investigador/a), bem como sistematizar orientações e recomendações no sentido de minimizar qualquer possibilidade de a investigação promover qualquer tipo de revitimação. Assim sendo, começaremos por analisar e debater as principais implicações que uma experiência de vitimação poderá acarretar para as suas vítimas para, de seguida, refletirmos sobre as questões éticas subjacentes à produção da investigação científica com esta população, e, por fim, identificar os principais cuidados e recomendações a atender neste sentido.

\section{VÍTIMAS DE VIOLÊNCIA E DE CRIME: EFEITOS E IMPACTO}

Volvidos cerca de 20 anos do nascimento da vitimologia científica é apenas nos anos 70 que o Conselho da Europa começou a evidenciar alguma preocupação com as questões da vitimação, envolvendo-se numa procura ativa de diferentes respostas que permitissem salvaguardar os direitos e interesses das vítimas dos vários Estados membros (Saavedra, 2016). Por esta altura, assinala-se também a emergência de vários estudos de vitimação (Fattah, 2000), os quais visavam determinar o volume da vitimação e conhecer as características sociodemográficas das vítimas de crime, permitindo assim identificar padrões de vitimação e traçar a distribuição espacial e social de determinados tipos de crime (Kersteren \& Van Dijk, 2010; Killias, 2001 citados por Saavedra, 2016).

Em virtude dos avanços que se foram registando nesta área da vitimação, dispomos hoje de um vasto conhecimento acumulado em torno do impacto das múltiplas formas de vitimação às quais as pessoas podem ser sujeitas, com ou sem natureza criminal.

Em termos genéricos têm sido identificadas três principais formas de vitimação: direta, secundária e vicariante (Machado \& Gonçalves, 2002). A vitimação direta, que resulta do encontro entre um ofensor e uma vítima durante a ocorrência de um crime, sendo a vítima direta aquela que experiencia as consequências do ato criminal em primeira mão (Karmen, 2012). A vitimação secundária é desencadeada pelo tipo de resposta que é providenciada à vítima (Orth, 2002), seja mediante o recurso a atitudes, a comportamentos ou a práticas suscetíveis de potenciar o trauma (cf. Caridade \& Sani, 2016) e, neste sentido, a própria investigação científica, quando pautada por procedimentos éticos menos rigorosos e com potencial interferência no bem-estar emocional dos/as participantes, poderá fomentar esta forma de vitimação nos sujeitos participantes. Efetivamente, a literatura tem vindo a comprovar que os/as participantes com histórias de violência são considerados/as populações mais vulneráveis na medida em que ter de relatar, em contexto de investigação, essas experiências de vitimação traumáticas, constitui sempre um esforço particularmente exigente e suscetível de desencadear trauma secundário (e.g., Campbell, Adams, Wasco, Ahrens, \& Sefl, 2010; Shorey, Cornelius, \& Bell, 2011), algo que terá de ser devidamente acautelado e gerido no decorrer da pesquisa (conforme iremos problematizar no ponto seguinte).

Por sua vez, a vitimação vicariante surge para incluir a experiência das consequências da vitimação ocorrida a outra(s) pessoa(s) (Machado \& Gonçalves 2002). A vitimação vicariante tem sido também designada de vitimação indireta, referindo-se assim à vitimação que ocorre, por exemplo, quando alguém testemunha incidentes de violência (e.g., como agressão ou abuso) ou está sujeito a um ambiente geral de perigo ou experiencia medo criado por níveis elevados de conflito e violência numa comunidade (Sani, 2016).

A estes três tipos de vitimação, acrescente-se também a vitimação terciária (Scherer \& Scherer, 2016, p. 542-543) como sendo aquela em que "a vítima sofre as consequências não unicamente do delito propriamente fático; não exclusivamente do Estado e dos aparatos estatais, que se mostram ineficientes e inócuos no combate e suporte necessários à vítima; mas também do estigma do seu grupo social, da sua família, do seu trabalho, dos amigos e vizinhos"; e, ainda, a vitimação múltipla cujo termo surge em resposta à evidência de que uma forma de violência está quase sempre associada a outras experiências abusivas, comprovando-se que a experiência singular de um só tipo de abuso é muito rara (e.g., Finkelhor, Ormrod, Turner, \& Hamby, 2005). Outros conceitos há que têm sido utilizados para descrever a experienciação de múltiplas formas de violência, como sejam: vitimação cumulativa, vitimação repetida, polivitimação (cf. Matos, 2016).

Independentemente das diversas formas de vitimação ou da gravidade do ato que lhe deu origem, é sabido que qualquer processo de vitimação se caracteriza pela sua complexidade, o que justifica, desde logo, uma análise minuciosa às suas consequências e impacto (cf. Saavedra, 2016). Assim, as consequências remetem para a análise do dano causado pelo ato criminal, seja material, físico ou 
psicológico; já o impacto diz respeito à avaliação (subjetiva) que a vítima constrói acerca do que lhe aconteceu (Dignan, 2004) com influência clara na forma como esta se irá percecionar.

Em termos genéricos, os danos físicos e materiais poderão divergir consoante o tipo de vitimação em causa sabendo-se, contudo, que as repercussões emocionais podem assumir grande relevância e significância mesmo nos crimes menos graves, sem que se verifique uma correspondência direta entre o dano físico, material e a vivência emocional do evento (Peters, 1988, citado por Machado \& Gonçalves, 2002). De entre as diversas consequências e efeitos decorrentes das experiências de vitimação, tem sido identificados diversos problemas mentais (e.g., ansiedade, depressão, desordem de stresse póstraumático, perturbações alimentares, risco de suicídio, etc.), problemas de saúde física (e.g., injúrias diretas, efeitos gastrointestinais, cardiopulmonares, efeitos ao nível da saúde reprodutiva, maternal, gestacional, etc.), acrescido do facto de a experiência de vitimação poder incrementar uma maior vulnerabilidade para a revitimação (cf. Priester, Cole, Lynch, \& DeHart, 2016). Outros autores (e.g., Machado \& Gonçalves, 2002) apontam ainda reações como o choque, a angústia, o medo e a raiva.

Por sua vez, o impacto da vitimação não depende exclusivamente do tipo e gravidade do delito, mas poderá ser afetado por outras variáveis, de que são exemplo as características prévias da própria vítima, sejam certas características sociodemográficas (mulheres, crianças e idosos experienciam consequências mais severas decorrentes da experiência de vitimação), sejam o grau/capacidade de ajustamento da vítima, as anteriores experiências de vitimação ou mesmo o maior nível de stresse surgem como outras variáveis que poderão interferir de forma negativa com a capacidade das vítimas para gerir a experiência criminal (cf. Machado \& Gonçalves, 2002). Acresce ainda, as respostas pós vitimação, quer por parte das vítimas ou mesmo dos seus familiares, e as quais poderão desempenhar um papel determinante no impacto da experiência de vitimação. De entre as diferentes respostas, destaca-se o estilo atribucional, sendo que quando caracterizado por grande sentido de culpabilização, tende a gerar mais problemas psicológicos (e.g., ansiedade, depressão, sentimentos de impotência, desânimo) e o tipo de suporte, formal ou informal, prestado às vítimas (Machado \& Gonçalves, 2002). Assim, é sabido que o apoio e suporte familiar são fundamentais para a recuperação da vítima, contudo quando também este é afetado pela experiência de vitimação (vitimação indireta) não poderá produzir os efeitos desejados. Por sua vez, a forma como o sistema judicial lida com as vítimas, sobretudo pelo tipo de resposta indicado, poderá igualmente fomentar uma revitimação (vitimação secundária).

Uma revisão recente da literatura (cf. Priester et al., 2016) em torno dos efeitos e consequências da vitimação comprovou, ainda, que estes não são específicos de um único grupo económico, étnico ou cultural, da mesma forma que não os afeta de igual modo. De forma mais concreta, no caso das mulheres as consequências da vitimação tendem a ser mais frequentes, mais severas e mais nefastas comparativamente ao verificado no sexo oposto. Além disso, uma revisão sistemática da literatura (e.g., Collier, van Beusekom, Bos, \& Sandfort, 2013) em torno dos efeitos psicossociais e físicos sobre a vitimação por pares, considerando a orientação sexual e identidade/expressão de género dos adolescentes, e a qual envolveu estudos provenientes de 12 países, revelou que os grupos considerados minoritários em termos sexuais, económicos e étnicos tendem a experienciar efeitos tão ou mais severos em termos de vitimação, comparativamente aos grupos tidos como maioritários. Tal tem sido atribuído à reação social à vitimação, que, por via da estigmatização e minimização das suas experiências de vitimação, condiciona não só o relato destas experiências abusivas, mas também a procura de ajuda e tratamento (e.g., Miller Canales, Amacker, Backstrom, \& Gidycz , 2011; Stevens, Gerhart, Goldsmith, Heath, Chesney, \& Hobfoll, 2013). Efetivamente, tem sido demonstrado que o estigma social (seja pelas próprias vítimas, companheiros, família e amigos, comunidade ou mesmo pelas instituições) associado à violência de género (sobretudo no caso da violência praticada pelo/a parceiro/a íntimo/a), poderá funcionar como um mecanismo de controlo social e, nesta medida, tende não só a exacerbar o impacto na saúde física e mental, como também promove a possibilidade de revitimação (Barnett, Maticka-Tyndale, \& Kenya, 2016; Miller et al., 2011).

Em suma, fica claro que uma mesma experiência de vitimação por diferentes vítimas poderá ser vivida e significada de modos muito diferentes, acarretando impactos distintos e necessidades também elas diferentes no decorrer do processo de recuperação de cada vítima (Pina, 2016). Além disso, a reação social à vitimação poderá condicionar o relato das experiências abusivas. A forma como cada vítima irá encarar a sua participação numa qualquer investigação científica poderá divergir, inviabilizando qualquer tipo de procedimento rígido nesta matéria. Importa, assim, analisar as principais questões éticas que se colocam na investigação com vítimas, bem como apresentar algumas recomendações a adotar neste sentido. Neste trabalho, focar-nos-emos nas questões éticas no que respeita à vitimação adulta (particularmente na violência ocorrida na intimidade), na medida em que a pesquisa junto de crianças reúne outras especificidades e que de resto já foram sobejamente retratadas em outros trabalhos académicos (e.g., Fernandes, 2016; Sani, 2001). 


\section{CONSIDERAÇõES E RECOMENDAÇõES ÉTICAS NA INVESTIGAÇÃO COM VÍTIMAS ADULTAS}

Dadas as inegáveis implicações nefastas que a experienciação de violência e de crime poderá ter nas suas vítimas, bem como a complexidade e multicausalidade que está subjacente aos diversos fenómenos de vitimação e ainda a maior fragilidade e vulnerabilidade que, não raras vezes, caracterizam as populações que enfrentam estas adversidades, torna-se fundamental que a condução de uma qualquer investigação neste domínio observe um maior cuidado no que às questões éticas diz respeito. Outros desafios contribuem para a complexidade da investigação neste âmbito, nomeadamente no que respeita às questões relacionadas com a segurança, o recrutamento dos/as participantes e as estratégias de amostragem (e.g., onde encontrar as vítimas?) (Bender, 2016; Btoush \& Campbell, 2009). Não obstante, isto não implica necessariamente que tenha que se proceder a uma exclusão destas populações da investigação vitimológica, até porque tal poderia promover um certo paternalismo ou superproteação deste tipo de vítimas, interferindo assim com a oportunidade de poderem partilhar a sua experiência e assim contribuir para a prevenção dos fenómenos de vitimação (Clark \& Walker, 2011; Fernandes, 2016). Importa, sim, que haja por parte dos/as investigadores/as maior sensibilidade e capacidade para ir gerindo os diferentes desafios éticos que surgem no decorrer da pesquisa, incluindo os riscos e benefícios do conhecimento que irá ser produzido, tomando sempre em consideração todas as questões culturais e contextuais que, por vezes, parecem colidir como o código de ética vigente (Bender, 2016). Só desta forma será possível garantir e preservar a integridade e dignidade dos/as potenciais participantes e mitigar a possibilidade de a sua participação na pesquisa poder constituir uma forma de revitimação.

Indubitavelmente, qualquer investigação, independentemente do seu objeto de análise, deverá pautar-se por um determinado código de ética em função da área em que se encontra a investigar. $\mathrm{Na}$ área da psicologia, destacamos as guidelines internacionais estipuladas pela American Psychological Association (APA) e, no contexto português, contamos ainda com o contributo do Código Deontológico da Ordem dos Psicólogos Portugueses (OPP), que no seu princípio sete elenca as diferentes diretrizes a seguir em matéria de investigação produzida pelos psicólogos (OPP, 2016). A não inclusão ou desrespeito por estas normas poderão ocasionar a fragilidade do trabalho de pesquisa. Não obstante, tem sido defendido que a observância destas guidelines é insuficiente para fazer face a todas as complexidades com as quais o/a investigador/a se defronta no decorrer da pesquisa (Clark \& Walker, 2011; Fernandes, 2016; Fontes, 2004).

Quando a investigação envolve populações especialmente vulneráveis (e.g., Ferreira, Buttell, \& Ferreira, 2015; Fleischman \& Wood, 2002; Rafael \& Moura, 2013; Schraiber, d'Oliveira, \& Couto, 2009) como poderá ser o caso das vítimas de violência e de crime (sobretudo quando envolve crianças, mulheres e idosos) ou situações potencialmente traumáticas e/ou stressantes (Legerski \& Bunnell, 2010), tem sido amplamente defendido que a pesquisa deverá considerar cuidados particulares e redobrados. Desde logo, é consensual que terá de haver uma observação atenta e detalhada e um total respeito pelos princípios da beneficência e não maleficência, da justiça e equidade (e.g., Clark \& Walker, 2011; Fontes, 2004; Rafael \& Moura, 2013).

Clark e Walker (2011) defendem, por sua vez, uma abordagem mais alargada nesta matéria, considerando que as preocupações de natureza ética não devem centrar-se apenas nos aspetos relacionados com a implementação do estudo (tais como a questão da segurança dos/as participantes e da relação entre participantes e investigadores/as), mas deverão abranger as diferentes etapas inerentes à realização de um estudo (desde o seu planeamento/desenvolvimento, implementação, análise e disseminação dos seus resultados), destacando em particular a forma como os resultados são publicados e disseminados em termos das suas implicações práticas e políticas de prevenção dos fenómenos vitimológicos. A título exemplificativo, os autores supracitados apontam a estratégia analítica utilizada em estudos de prevalência, nomeadamente o facto de, por vezes, não se desenvolverem análises estatísticas mais complexas e que permitam um conhecimento mais aprofundado sobre a relação entre determinadas variáveis; o tipo de amostragem utilizada (recurso a amostras da comunidade, amostras clínicas e institucionais, estudos de caso, entre outros) e de como esta poderá enviesar o conhecimento produzido sobre uma determinada temática; ou ainda o contexto onde é produzida uma determinada investigação.

Tendo por base as diversas recomendações que vão sendo divulgadas quer pelos diversos trabalhos académicos produzidos neste âmbito, quer por organizações que defendem os interesses e direitos das vítimas, como é o caso da Organização Mundial de Saúde, passamos a apresentar um conjunto de cuidados e orientações a atender na condução de estudos de natureza vitimológica, mais concretamente ao nível: da interação com os/as participantes e das competências exigidas ao/à investigador/a. 


\section{Interação com os/as participantes}

Ao nível da interação com os/as participantes dos estudos, a preservação da segurança das vítimas (sobretudo nos casos da violência íntima) surge identificada como preocupação primordial na condução de qualquer estudo (Clark \& Walker, 2011), devendo, segundo a Organização Mundial de Saúde (WHO, 2001), orientar todas as decisões da pesquisa. Desde logo, importa acautelar o risco de revitimação da vítima em virtude da sua participação na pesquisa, implicando isto que se considerem diferentes tipos de questões: como contactar primeiramente a vítima para participar no estudo?; onde é que a recolha de dados irá ser realizada?; como promover a segurança da vítima antes, durante e depois da sua participação no estudo?; no caso dos estudos longitudinais como contactar, de forma segura, a vítima no decorrer do processo de pesquisa? (Sullivan \& Cain, 2004).

De forma mais concreta, na investigação com vítimas de violência íntima, que envolva a realização de entrevistas, há aspetos que merecem particular atenção no sentido da preservação da privacidade das mesmas: desde logo, exige que haja alguma criatividade por parte do/a investigador/a, tempo e outros recursos adicionais de forma a encontrar o local mais apropriado para tal e que seja isento de ruídos ou outras intromissões que possam não só comprometer a segurança da vítima mas também condicionar a recolha de dados (e.g., unidades de cuidados de saúde, contextos universitários, etc.); caso se perspetive qualquer constrangimento ao nível da privacidade e segurança, deve ser dada oportunidade à vítima para reprogramar a entrevista e o local da mesma; no caso em que as vítimas tenham consigo os filhos, poderá ser necessário mobilizar outros elementos da equipa de pesquisa para interagir com as crianças durante o tempo da entrevista (e.g., Btoush \& Campbell, 2009; Ellsberg \& Heise, 2002). Em casos em que se verifique a necessidade de contactar a vítima por telefone, deve o/a investigador/a precaver situações em que o/a agressor/a possa atender as chamadas, sem nunca revelar o verdadeiro conteúdo do telefonema (e.g., poderá por exemplo dizer que está a preparar um estudo sobre questões de saúde); no caso do recurso a guiões de entrevista, estes deverão conter questões alternativas neutras e que possam ser usadas caso o/a agressor/a surja de forma inesperada no decorrer da entrevista; se o estudo tiver previsto algum tipo de compensação económica, evitar o uso de cheques e entregar a compensação em numerário; perante algum tipo de risco iminente para o/a participante, este/a deverá ser excluído do estudo (Fontes, 2004).

A garantia da confidencialidade é um outro aspeto deveras relevante e essencial para assegurar a proteção da vítima, mas também a qualidade dos dados. Neste sentido, o/a investigador/a deve ter o particular cuidado de não anotar em momento algum o nome do/a participante - criar códigos para cada questionário; no caso das entrevistas, geralmente gravadas, deve haver o cuidado de acordar inicialmente um nome fictício com o/a participante o qual será utilizado no decorrer da entrevista; se, por algum motivo (por exemplo para efeitos de recrutamento dos/as participantes para um estudo subsequente) houver necessidade de recolher algum dado identificativo do/a participante, essa informação deve ser separada do questionário (tal como o consentimento informado, que abordaremos de seguida) (WHO, 2001). Há autores (Fontes, 2004) que defendem inclusive a possibilidade de o consentimento informado poder ser dado verbalmente ou mesmo o recurso a nomes fictícios por parte dos/as participantes, de forma a prevenir eventuais perdas de confidencialidade.

No caso da recolha online dos dados (recurso ao questionário tipo survey), devem ser adotadas estratégias que permitam garantir a segurança dos mesmos (e.g., criar ficheiros protegidos com recurso a passwords, encriptação dos ficheiros que contêm os dados), devendo estes estar apenas disponíveis aos/às investigadores/as responsáveis pelos estudos (Btoush \& Campbell, 2009). Além disso, é importante definir um período de tempo durante o qual o questionário estará disponível para efeitos de recolha de dados, sendo que uma vez findo este prazo, deverá ser retirado da internet.

Concomitantemente, o consentimento informado, que deve ser livre e esclarecido, além de reforçar o compromisso ético dos/as investigadores, pode favorecer o início da formação do vínculo entre o/a investigador/a e o sujeito (Rafael \& Moura, 2013) e, como tal, deve estar devidamente empossado de critério e rigor (Fonte, 2004). Desde logo, é importante que se proceda a uma exposição clara dos objetivos do estudo, do processo do mesmo, das suas possíveis contribuições e, obviamente, do anonimato e da liberdade de participação no estudo. Tal possibilitará o empoderamento dos indivíduos com informações com clara influência na decisão em participar ou não da pesquisa. Deve ainda ser usada uma linguagem acessível e de forma que garanta a autonomia dos possíveis sujeitos participantes - notese que a simples entrega do consentimento informado não é garantia disso; dar a possibilidade aos/às participantes de poderem dirimir possíveis dúvidas relacionadas com o documento, de poderem consultar a opinião dos seus familiares, bem como indicar os reais benefícios que podem ser esperados com a sua participação na pesquisa. Aquando da obtenção do consentimento informado, o estudo deve ser apresentado como visando a análise da saúde das pessoas/mulher em particular, experiências de vida ou relações familiares, sublinhando-se ainda de que poderão ser confrontados/as com questões 
particularmente sensíveis e difíceis de abordar, mas de que uma forma geral, as pessoas consideram importante falar sobre estes aspetos (Ellsberg \& Heise, 2002). Note-se que aceitar falar sobre as suas experiências de vitimação implica recordá-las e muitos sujeitos aceitam participar no estudo sem perspetivar que tal poderá acarretar desconforto e mau estar. De forma a precaver este tipo de situações, há autores (e.g., Carlson, Newman, Daniels, Armstrong, Roth, \& Loewenstei, 2003; Newman, Risch, \& Kassam-Adams, 2006) que defendem a necessidade de se providenciar informação aos/às participantes sobre a natureza das questões colocadas e de que estas poderão provocar algum desconforto emocional, pois tal permitirá fomentar o rigor da pesquisa e autonomia dos/as participantes. Deverá ainda ser referido que, se tal entenderem e necessitaram, os/as participantes terão ao seu dispor o devido apoio. Além disso, convém relembrar os/as participantes que a participação é voluntária e que têm em seu poder a decisão de desistir em qualquer momento do estudo ou optar por não responder às questões apresentadas.

Habitualmente, aos/às participantes é dada uma cópia do consentimento informado, contudo este procedimento deverá ser devidamente ponderado em função das especificidades de cada caso, sendo que nalgumas situações (e.g., violência íntima) tal poderá comprometer a segurança da vítima (Btoush \& Campbell, 2009).

Sempre que os dados forem recolhidos via online, o consentimento informado deve ser substituído pelo assentimento na participação do estudo, e em que depois de uma primeira explicação sobre o estudo, seus objetivos e procedimentos inerentes, o/a participante assinala com uma cruz em espaço próprio se concordar com os termos que em irá decorrer o estudo.

A propósito dos benefícios, há que referir que geralmente estes são de longo prazo e aos/às participantes interessam que os estudos também possam oferecer algum tipo de suporte imediato. 0 esclarecimento e a devolução de informação (e.g., recursos e apoios sociais existentes para o fenómeno em causa) constituem cuidados éticos fundamentais no controlo do potencial impacto da pesquisa no bem-estar emocional do/a participante. Neste sentido, sugere-se que o desenho do estudo procure incluir, na medida do possível, ações destinadas a reduzir qualquer desconforto causado aos/às participantes pela pesquisa, como por exemplo, encaminhar os/as participantes, que assim o desejem, para receberem algum tipo de apoio junto de instituições e/ou profissionais indicados para tal.

A discussão em torno dos benefícios que a participação num determinado estudo pode ter releva para a análise do princípio da beneficência, o qual estipula que se prevejam benefícios para os/as participantes, mas também se procure contrabalançar esses benefícios em função dos riscos que a participação numa investigação pode ter. Assim, Fontes (2004) apresenta várias recomendações neste sentido, tais como: i) os benefícios devem ser diretos, imediatos e os mais concretos possíveis; ii) os/as investigadores/as deverão procurar encontrar benefícios que se adequem às características dos/as participantes (por exemplo, se para alguns a compensação monetária é importante, para outros/as determinados objetos simbólicos poderão funcionar como ótimas recompensas), iii) os/as investigadores/as deverão providenciar informação adequada sobre o tema em análise (e.g., distribuindo panfletos informativos, informar sobre os serviços de apoio existentes, entre outros).

Paralelamente, o princípio da não maleficência pressupõe que os benefícios deverão superar os riscos de dano e que o bem-estar dos/as participantes se sobreponha aos interesses científicos. A análise deste princípio remete, assim, para análise de eventuais danos que a investigação pode acarretar para os/as seus/suas participantes, mais concretamente, o risco de eventual revitimação ou de experienciação de stresse emocional, mas também envolve a discussão em torno dos danos que se poderão colocar ao/à investigador/a, nomeadamente problemas de contratransferência ou mesmo do hiperenvolvimento do/da investigador/a (Fontes, 2004). Assim, no que respeita ao risco de retraumatização dos/das participantes, uma metanálise de estudos vitimológicos (Newman \& Kaloupek, 2004) acerca dos riscos e benefícios da participação na pesquisa permitiu concluir que os benefícios (e.g., obter informação sobre os fenómenos, usar a sua experiência para ajudar os outros, aumentar a sua consciencialização acerca das suas histórias passadas, etc.) associados à participação numa determinada investigação superam os seus riscos (e.g., experienciar emoções negativas e stresse). Por sua vez, os estudos empíricos conduzidos neste domínio, seja junto de mulheres vítimas de agressão sexual (e.g., Campbell et al., 2010) ou mesmo no contexto da violência no namoro (e.g., Shorey et al., 2011), tem revelado que as vítimas percecionam a sua participação na pesquisa como sendo de reduzido stresse, encarando-a igualmente como positiva e benéfica. Não obstante, tem sido igualmente demonstrado que os benefícios desta participação parecem diminuir perante histórias de vida mais adversas e particularmente traumáticas (Maia, Graça, Cunha, Ribeiro, Mesquita, \& Antunes, 2008). Outros estudos há (e.g., Carlson et al., 2003) que, pese embora 70\% dos/as participantes apresentassem níveis baixos de stresse face à sua participação num estudo relativo a experiências traumáticas e 50\% qualificassem mesmo a sua participação como positiva, foram detetados níveis moderados a elevados de aborrecimento quanto confrontados/as com questões relativas à 
sintomatologia traumática passada e atual. Não obstante, esta é uma matéria que carece de maior evidência científica, apoiada sobretudo em estudos de caráter longitudinal (Fontes, 2004).

Note-se ainda que a postura apresentada pelo/a participante no início de qualquer estudo, em que ora manifestam uma vontade expressa em abordar o tema, expondo o seu sofrimento na esperança de conseguir algum tipo de ajuda ou conforto, ora mostram um certo receio em falar sobre o problema ou da recaída, poderá interferir na participação (Rafael \& Moura, 2013). A este respeito, Fontes (2004) enumera diversas situações (participantes recluídos/as, inseridos/as em instituições de tratamento) em que os/as participantes se poderão sentir de alguma forma coagidos a participar no estudo por considerarem que o mesmo trará benefícios diretos para a sua situação, ou mesmo quando são inquiridos por pessoas que ocupam posições de autoridade (e.g., polícias, guardas prisionais, psicoterapeutas), sendo que nestes casos terá que haver cuidados adicionais na obtenção do consentimento informado. Assim, importa desde logo que os/as investigadores/as se certifiquem de que não estão a exercer qualquer tipo de influência e/ou autoridade sobre o/a participante, ou mesmo indicar qualquer convicção relacionada com o impacto do estudo, de que este não resultará em qualquer tipo de dano para o/a participante ou mesmo transmitirem informação de que os/as profissionais sabem o que fazem; considerar eventualmente a possibilidade de a entrevista ocorrer num outro local e ser realizada por outra pessoa, garantindo-se sempre que o processo compreende a obtenção de consentimento, bem como a opção de retirada/abandono do mesmo, se assim entender; informar devidamente os/as participantes sobre a secção e/ou tipo de questões relacionadas com a violência, dando-lhes sempre a possibilidade de escolherem responder (Fontes, 2004).

\section{Competências dos/as investigadores/as}

O papel do/a investigador/a assume-se como sendo crucial nesta matéria, sobretudo pela sensibilidade e capacidade para saber identificar e gerir, de forma equilibrada e harmoniosa, os diferentes desafios éticos que se colocam no decorrer da pesquisa, desde a elaboração dos seus objetivos até às implicações práticas dos estudos e subsequentes políticas preventivas/interventivas que deles poderão resultar, bem como a disseminação dos seus resultados. Para tal, é fundamental que o/a investigador/a desenvolva um conjunto de competências, fundamentais para afirmar o rigor ético da pesquisa, e as quais se poderão situar a três níveis: técnicas, relacionais e individuais.

Ao nível das competências técnicas é, desde logo, fundamental que o/a investigador/a obtenha conhecimentos essenciais sobre as questões legais subjacentes aos diferentes fenómenos vitimológicos e criminais, sendo que nalgumas situaç̧ões poderá ter de denunciar/participar às autoridades competentes situações abusivas (Fraga, 2016). Mais concretamente, refira-se as situações em que os/as profissionais têm o dever legal (no caso dos crimes públicos) ou moral em reportar às autoridades os casos que representam risco ou perigo (e.g., maus tratos a crianças, idosos, violência doméstica ou situações em que se verifique perigo para o/a participante e para terceiros). Neste sentido, e ainda que, por vezes, os/as investigadores/as recorram a diferentes estratégias para evitar este tipo de dilemas (e.g., marcação de entrevistas aleatoriamente ou recurso a técnicas de entrevista aleatórias), tem sido sustentada a necessidade de os/as investigadores/as informarem previamente os/as participantes de que as situações que representem perigo para si ou para terceiros terão que ser reportadas às autoridades competentes ou mesmo o facto de elaborarem um protocolo em que todas estas questões sejam cuidadosamente pensadas (Fontes, 2004).

A acrescer a isto, e porque compete ao/à investigador/a o planeamento dos estudos e identificação dos respetivos objetivos, é fundamental que este reúna conhecimentos técnicos que lhe permitam fundamentar devidamente as suas opções. Assim, e dada sensibilidade inerente aos temas que envolvem situações de violência e de crime, a condução de um qualquer estudo neste domínio deve revelar-se estritamente necessária e justificável pela sua pertinência e relevância para a área científica em causa (Fraga, 2016). Caso contrário, os procedimentos inerentes à pesquisa poderão promover uma vitimação secundária. Ademais, os estudos de prevalência precisam de ser metodologicamente planeados e baseados no conhecimento da experiência atual sobre como minimizar a subnotificação de violência tão frequente perante certos tipos de vitimação, sobretudo a que assume maior gravidade (WHO, 2001) ou quando esta afeta sobretudo os grupos considerados minoritários (e.g., Miller et al., 2011; Priester et al., 2016). A este respeito, cabe referir que o relato das situações abusivas é em grande medida determinado pelo tipo de questões colocadas e, neste sentido, importa evitar o uso de certos termos (e.g., como abuso, estupro, violência) e optar por questionar antes sobre se já experienciou/já foi alvo de diferentes tipos de atos/comportamentos; questionar ainda sobre o local onde ocorreram esses comportamentos (casa, escola, comunidade) e por quem foram praticados (familiar, parceiro/a, ex-parceiro/a, filho/a, etc.) (WHO, 2001). 
Uma outra competência técnica do/a investigador/a envolve a necessidade de este desenvolver previamente a elaboração do projeto/protocolo de investigação, submetendo-o ao escrutínio de uma Comissão de Ética (e.g., preferencialmente da instituição onde irão ser recolhidos os dados e, na ausência desta entidade, submeter à da comissão de ética da instituição universitária onde o estudo se encontra a ser desenvolvido), de forma a triar eventuais problemas éticos e deontológicos inerentes à pesquisa.

Como referido anteriormente, é extremamente importante que os elementos que integram a equipa de investigação sejam cuidadosamente selecionados e recebam formação apropriada (Ellsberg \& Heise, 2002; Fleischman \& Wood, 2002; Fraga, 2016; WHO, 2001; Schraiber et al., 2009), até para minimizar eventuais danos que possam advir do processo investigativo (Fontes, 2004). Uma adequada preparação dos/as entrevistadores/as que lidam com as questões da violência deve envolver duas etapas (Campbell, Adams, Wasco, Ahrens, \& Sefl, 2009; Fraga, 2016): a primeira inclui formação e conhecimento sobre as dinâmicas e especificidades inerentes aos diferentes tipos de violência interpessoal (e.g., conhecer as causas da violência, os mitos e factos, a diversidade e sensibilidade cultural, a intervenção em crise, o plano de segurança e recursos e apoios sociais). Por exemplo, no que respeita à temática da violência íntima, importa providenciar informação adequada sobre esta (e.g., os estereótipos de género, a questão da desigualdade, contactos e suporte socioassistencial, entre outros). A segunda etapa passa por ensinar e treinar a condução de entrevistas, recorrendo a diferentes estratégias para tal (e.g., visualizar entrevistas realizadas por especialistas, role play) (Campbell et al., 2009). Segundo as perspetivas feministas, as entrevistas conduzidas junto de mulheres maltratadas e de outras vítimas de trauma devem assentar num conjunto de estratégias que incrementem a proteção e o empowerment dos/as participantes (cf. Burgess-Proctor, 2015), tais como: i) solicitar aos/às participantes que escolham os pseudônimos a usar no decorrer das entrevistas, sendo que tal irá possibilitar não só diminuir a relação hierárquica entre investigador/a e participante, mas também permitir que os/as participantes exerçam a sua "voz" no processo de pesquisa; ii) recorrer a técnicas favorecedoras da revelação das situações abusivas nos/as participantes, constituindo esta também uma importante estratégia para fomentar o empowerment; iii) fornecer aos/às participantes certificados de participação no estudo, ponderando-se sempre eventuais riscos que tal possa ter na sua segurança (perante o mínimo indício de risco de violência, optar pela não emissão dos certificados); iv) expressar e retribuir emoção para com os/as participantes, fomentando assim o conforto com a revelação e conferindo importância aos seus relatos; e, v) concluir as entrevistas reforçando a coragem dos/as participantes pela partilha de informação e participação no estudo (e.g., pedir aos/às participantes para deixar mensagens para outros/as participantes que possam ter vivenciado situações similares).

Acrescem ainda outros cuidados a adotar pelos/as investigadores/as responsáveis pela recolha de dados, como sejam: evitar pré-juízos ou julgamentos na forma como as questões são elaboradas; evitar linguagem que possa julgar, censurar, responsabilizar, estigmatizar a vítima; saberem lidar, gerir com a reação emocional das vítimas às questões colocadas; aumentar as oportunidades para o/a entrevistado/a dar a sua opinião (por exemplo incluindo itens abertos); explorar os diferentes tipos de violência (física, psicológica e sexual de forma separada); nunca entrevistar a vítima na presença de outra pessoa; procurar terminar a entrevista de forma positiva, reforçando a vítima pelas estratégias de coping utilizadas para lidar com a situação e demonstrando-lhe que a sua participação será útil para ajudar outro tipo de vítimas; os/as investigadores devam ainda estar instruídos sobre os recursos e apoios existentes de forma a transmitirem essa informação aos/às participantes (Schraiber et al., 2009). Tal implicará que estes devem informar-se previamente de todos os recursos/mecanismos sociais, legais, de saúde existentes e os mesmos devem ser apresentados a todos os/as participantes (seja oralmente ou recorrendo a materiais elaborados para o efeito, como por exemplo, recurso a panfletos). Um outro aspeto deveras crucial relaciona-se com a necessidade de os/as investigadores/as possuírem o dever ético de se assegurarem que os dados das pesquisas são devidamente interpretados e permitem retirar ilações para o desenvolvimento de políticas e medidas interventivas na problemática em estudo (Clark \& Walker, 2011).

Ao nível das competências relacionais, invoca-se sobretudo o imperativo sustentado pelas abordagens feministas, nomeadamente, a necessidade de se promover uma relação colaborativa entre as partes e que permita criar oportunidades de empoderamento dos/as participantes (Campbell et al., 2010). Para tal, tem sido sugerido o recurso a diferentes tipos de estratégias que possam diminuir os diferenciais de poder que se tendem a estabelecer no decorrer do processo de investigação entre as partes envolvidas, tais como: o recurso à reflexividade, ou seja, a necessidade de o/a investigador/a adotar uma postura analítica e de interrogação constante acerca de como o contexto social poderá interagir e influenciar a pesquisa; a adoção por um cuidado ético, que implica uma postura de orientação de suporte e apoio para com os/as participantes selecionados para o estudo, fomentando, deste modo, o desenvolvimento de uma relação mais igualitária e colaborativa entre investigadores/as e participantes; 
e, ainda, promover a justiça social e mudança social, ou seja, a investigação deverá procurar promover a justiça e a igualdade para as mulheres em geral, bem como para outros grupos socialmente marginalizados (cf. Burgess-Proctor, 2015).

Por fim, e em termos de competências individuais, identificam-se duas exigências fundamentais. Por um lado, a necessidade de os/as investigadores/as procurarem acautelar a sua segurança, à semelhança do discutido a respeito dos/as participantes, e a qual deve constituir uma preocupação transversal às diferentes etapas do processo investigativo (Clark \& Walker, 2011). Por outro lado, importa igualmente que os/as investigadores/as estejam capazes de lidar com os seus próprios preconceitos, medos e estereótipos. A autogestão emocional é igualmente necessária, sobretudo quando o/a investigador/a tem experiências similares.

\section{CONCLUSÃo}

Pese embora o indubitável contributo da investigação científica para o desenvolvimento e a implementação de políticas de apoio e proteção às vítimas de violência e de crime, é, pois, imperativo que os objetivos de qualquer estudo, seja de que natureza for, nunca se sobreponham ao bem-estar emocional dos/as participantes. 0 não respeito por este imperativo poderá não só promover uma revitimação dos/as participantes (sejam vítimas diretas ou indiretas), bem como debelar o exercício ético que deverá acompanhar a realização de uma qualquer investigação científica, comprometendo igualmente as implicações práticas que desta podem derivar. A este respeito, importa destacar os esforços desenvolvidos, sobretudo no contexto internacional, no sentido de produzir evidência científica que possa apoiar e regular as questões éticas na prática investigativa, mediante por exemplo o estudo da reação dos/as participantes à investigação (cf. Carlson et al., 2003; Newman, Willard, Sinclair, \& Kaloupek, 2001) e os quais devem ser alargados ao contexto português. A produção de trabalhos científicos aliados à organização de eventos públicos que permitam discutir e refletir sobre as questões éticas ao nível da investigação constituem importantes contributos para limar arestas neste domínio e promover o bemestar dos/as participantes durante o processo investigativo (Fontes, 2004).

Como bem defendem Rafael e Moura (2013, p. 290), "Não dedicar o tempo necessário a estas questões que podem trazer entraves para a realização da pesquisa em torno da ocorrência de violência, pode significar um retrocesso. Dar valor à ética na pesquisa pode ser um manifesto de vanguarda, mais uma contribuição inestimável da pesquisa para a sociedade atual e futura".

Exercitar os princípios da beneficência e não maleficência, da justiça e equidade constitui um cuidado ético fundamental e necessário à adoção de medidas protetivas das vítimas. Não obstante, importa considerar que a prática investigativa com vítimas não se pode limitar à mera salvaguarda dos códigos ou princípios de ética e em que, por vezes, resultado de uma análise desequilibrada entre os riscos e benefícios, as vítimas acabam por ser excluídas no processo investigativo, limitando assim a sua possibilidade de serem ouvidas e contribuir para a produção de conhecimento válido e necessário para a prevenção dos fenómenos vitimológicos. Ademais, na produção deste conhecimento constitui ainda um imperativo ético, atender a toda a diversidade sexual, social e cultural, no sentido de melhor identificar e compreender as características e os mecanismos que estão subjacentes às discrepâncias existentes em termos de efeitos do abuso entre os diversos grupos populacionais existentes.

\section{Referências}

Alberto, I. (2006). Maltrato e trauma na infância. Coimbra: Almedina.

Barnett, J., Maticka-Tyndale, E., \& Kenya, T. (2016). Stigma as social control: gender-based violence stigma, life chances, and moral order in Kenya. Social Problems, 0, 1-16. https://doi.org/10.1093/socpro/spw012

Bender, A. K. (2016). Ethics, methods, and measures in intimate partner violence research: The current state of the field. Violence Against Women, 1-32. https://doi.org/10.1177/1077801216658977

Btoush, R., \& Campbell, J. C. (2009). Ethical conduct in intimate partner violence research: Challenges and strategies. Nurs Outlook, 57, 210-216. https://doi.org/10.1016/j.outlook.2008.10.005

Burgess-Proctor, A. (2015). Methodological and ethical issues in feminist research with abused women: Reflections on participants' vulnerability and empowerment. Women's Studies International Forum, 48, 124-134. https://doi.org/10.1016/j.wsif.2014.10.014

Campbell, R., Adams, A. E., Wasco, S. M., Ahrens, C. E., \& Sefl, T. (2009). Training interviewers for research on sexual violence. A qualitative study of rape survivors'. Recommendations for interview practice. Violence Against Women, 15(5), 595-617. https://doi.org/10.1177/0886260507301332 
Campbell, R., Adams, A. E., Wasco, S. M., Ahrens, C. E., \& Sefl, T. (2010). "What has it been like for you to talk with me today?": The impact of participating in interview research on rape survivors. Violence Against Women, 16, 60-83. https://doi.org/10.1177/1077801209353576

Caridade, S. (2011). Vivências íntimas violentas. Uma abordagem científica. Coimbra: Editora Almedina.

Caridade, S., \& Sani, A. I. (2016). Vitimação secundária. In R. Maia, L. Nunes, S. Caridade, A. Sani, R. Estrada, C. Nogueira, H. Fernandes \& L. Afonso (Coord.), Dicionário Crime, Justiça e Sociedade (pp. 540). Lisboa: Sílabo.

Carlson, E. B., Newman, E., Daniels, J. W., Armstrong, J., Roth, D., \& Loewenstein, R. (2003). Distress in response to and perceived usefulness of trauma research interviews. Journal of Trauma \& Dissociation, 4(2), 131-142. https://doi.org/10.1300/J229v04n02_08

Clark, J. J., \& Walker, R. (2011). Research ethics in victimization studies: Widening the lens. Violence Against Women, 17(12), 1489-1508. https://doi.org/10.1177/1077801211436167

Collier, K. L., van Beusekom, G., Bos, H. M. W., \& Sandfort, T. G. (2013). Sexual orientation and gender identity/expression related peer victimization in adolescence: A systematic review of associated psychosocial and health outcomes. Journal of Sex Research, 50(3/4), 299-317. https://doi.org/10.1080/00224499.2012.750639.

Dignan, J. (2004). Understanding victims and restorative justice. England: Open University Press.

Doerner, W., \& Lab, S. (2012). Victimology (6 ${ }^{\mathrm{a}}$ ed.). Burlington: Anderson Publishing.

Ellsberg, M., \& Heise, L. (2002). Bearing witness: Ethics in domestic violence research. Lancet, 359(9317), 1599-1604. https://doi.org/10.1016/S0140-6736(02)08521

Fattah, E. (2000). Victimology: Past, present and future. Criminologie, 33(1), 17-46. https://doi.org/10.7202/004720ar

Fernandes, N. (2016). Ética na pesquisa com crianças: ausências e desafios. Revista Brasileira de Educação, 21(66), 759-779. https://doi.org/10.1590/S1413-24782016216639

Ferreira, R. J., Buttell, F., \& Ferreira, S. (2015). Ethical considerations for conducting disaster research with vulnerable populations. Journal of Social Work Values and Ethics, 12(1), 29-40.

Finkelhor, D., Ormrod, R. K., Turner, H. A., \& Hamby, S. L. (2005). Measuring poly-victimization using the JVQ. Child Abuse and Neglect, 29, 1297-1312. https://doi.org/10.1016/j.chiabu.2005.06.005

Fleischman, A. R., \& Wood, E. B. (2002). Ethical issues in research involving victims of terror. Journal of Urban Health, 79(3), 315-321. https://doi.org/10.1093/jurban/79.3.315

Fontes, L. A. (1998). Ethics in family violence research: Cross-cultural issues. Family Relations: Interdisciplinary Journal of Applied Family Studies, 47(1), 53-61. https://doi.org/10.2307/58485

Fontes, L. A. (2004). Ethics in violence against women research: The sensitive, the dangerous, and the overlooked. Ethics \& Behavior, 14(2), 141-174. https://doi.org/10.1207/s15327019eb1402

Fraga, S. (2016). Methodological and ethical challenges in violence research. Porto Biomedical Journal, 1(2), 77-80. http://dx.doi.org/10.1016/j.pbj.2016.04.005

Karmen, A. (2012). Crime victims: an introduction to vitimology (8 Ed.). Wadsworth: Cengage Learning.

Legerski, J. P., \& Bunnell, S. L. (2010). The risks, benefits, and ethics of trauma-focused research $\begin{array}{llll}\text { participation. } \quad \text { Ethics } & \text { Behavior, 20(6), }\end{array}$ http://dx.doi.org/10.1080/10508422.2010.521443

Machado, C. (2010a). Novas formas de vitimação criminal. Braga: Psiquilibrios Edições.

Machado, C. (2010b). Vitimologia: das novas abordagens teóricas às novas práticas de intervenção. Braga: Psiquilibrios Edições.

Machado, C., \& Gonçalves, R. A. (2002). Criminologia e vitimologia. In C. Machado e R. Gonçalves (coords.), Violência e vítimas de crimes (pp. 34-37). Coimbra: Quarteto Editora.

Maia, A., Graça, A., Cunha, A., Ribeiro, C., Mesquita, C., \& Antunes, J. R. (2008). Questões éticas no estudo da relação entre trauma e saúde: A investigação revitimiza as vítimas? In I. Leal, J. L. Pais Ribeiro, I. Silva \& S. Marques (Org.), Actas do 7ํㅡ Congresso Nacional de Psicologia da Saúde (pp. 111-114). Porto: Universidade do Porto. Retirado em 10 de dezembro de 2016 de https://repositorium.sdum.uminho.pt/bitstream/1822/7798/1/artigo\%20\%C3\%A9tica\%20trau ma.pdf

Matos, M. (2016). Vitimação múltipla. In R. Maia, L. Nunes, S. Caridade, A. Sani, R. Estrada, C. Nogueira, H. Fernandes \& L. Afonso (Coord.), Dicionário Crime, Justiça e Sociedade (pp. 538). Lisboa: Sílabo.

Miller, A. K., Canales, E. J., Amacker, A. M., Backstrom, T. L., \& Gidycz, C. A. (2011). Stigma-threat motivated nondisclosure of sexual assault and sexual revictimization: A prospective analysis. Psychology of Women Quarterly, 35(1), 119- 28. http://dx.doi.org/10.1177/0361684310384104.

Neves, A. S., \& Fávero, M. (2011). Vitimologia: ciência e activismo. Coimbra: Editora Almedina 
Newman, E., \& Kaloupek, D. G. (2004). The risks and benefits of participating in trauma focused research studies. Journal of Traumatic http://dx.doi.org/10.1080/10508422.2010.521443

Newman, E., Risch, E., \& Kassam-Adams, N. (2006). Ethical issues in trauma-related research: A review. Journal of Empirical Research on Human Research Ethics, 1(3), 29-46. http://dx.doi.org/10.1525/jer.2006.1.3.29

Newman, E., Willard, T., Sinclair, R., \& Kaloupek, D. (2001). The costs and benefits of research from the participants' view: The path to empirically informed research practice. Accountability in Research, 8, 27-47.

Ordem dos Psicólogos Portuguese (OPP) (2011, 2016). Código Deontológico. Lisboa: Ordem dos Psicólogos Portugueses. Retirado em 10 de fevereiro de file:///H:/OPP/web_cod_deontologico_pt_revisao_2016.pdf

Orth, U. (2002). Secondary victimization of crime victims by criminal proceedings. Social Justice Research, $15(4), 313-325$.

Pina, M. (2016). Vitimação. In R. Maia, L. Nunes, S. Caridade, A. Sani, R. Estrada, C. Nogueira, H. Fernandes \& L. Afonso (Coord.), Dicionário Crime, Justiça e Sociedade (pp. 534-535). Lisboa: Sílabo.

Priester, M. A., Cole, T., Lynch, S. M., \& DeHart, D. P. (2016). Consequences and sequelae of violence. In C. A. Cuevas \& C. M. Rennison (Eds.), The wiley handbook on the psychology of violence (pp. 100-129). USA: John Wiley and Sons, LTD. http://dx.doi.org/10.1002/9781118303092.ch6.

Rafael, R. M. R., \& Moura, A.T. (2013). Considerações éticas sobre pesquisas com mulheres em situação de violência. Revista Brasileira de Enfermagem, 66(2), 287-90.

Saavedra, R. (2016). Vitimação direta. In R. Maia, L. Nunes, S. Caridade, A. Sani, R. Estrada, C. Nogueira, H. Fernandes e L. Afonso (Coord.), Dicionário Crime, Justiça e Sociedade (pp. 536). Lisboa: Sílabo.

Sani, A. I. (2001). Reflexões sobre a ética na investigação qualitativa com crianças vítimas de violência. Infância e Juventude, 4, 127-132.

Sani, A. I. (2011a). Temas de Vitimologia: realidades emergentes e respostas sociais. Coimbra: Editora Almedina.

Sani, A. I. (2011b). Crianças vítimas de violência: representações e impacto do fenómeno. Porto: Edições UFP.

Sani, A. I. (2016). Vitimação vicariante. In R. Maia, L. Nunes, S. Caridade, A. Sani, R. Estrada, C. Nogueira, H. Fernandes e L. Afonso (Coord.), Dicionário Crime, Justiça e Sociedade (pp. 544-545). Lisboa: Sílabo.

Scherer, Z. A. P., \& Scherer, E. (2016). Vitimação terciária. In R. Maia, L. Nunes, S. Caridade, A. Sani, R. Estrada, C. Nogueira, H. Fernandes e L. Afonso (Coord.), Dicionário Crime, Justiça e Sociedade (pp. 542-544). Lisboa: Sílabo.

Schraiber, L. N., d'Oliveira, A. F., \& Couto, M. F. (2009). Violência e saúde: contribuições teóricas, metodológicas e éticas de estudos da violência contra a mulher. Cadernos de Saúde Pública, 25(2), 205-26. Retirado em 2 de setembro de 2016 de http://www.scielosp.org/pdf/csp/v25s2/03.pdf.

Shorey, R. C., Cornelius, T. L., \& Bell, K. M. (2011). Reactions to participating in dating violence research: Are our questions distressing participants? Journal of Interpersonal Violence, 26(14), 2890-2907. http://dx.doi.org/10.1177/0886260510390956

Stevens, N. R., Gerhart, J., Goldsmith, R. E., Heath, N., Chesney, S. A., \& Hobfoll, S. E. (2013). Emotion regulation difficulties, low social support, and interpersonal violence mediate the link between childhood abuse and posttraumatic stress symptoms. Behavior Therapy, 44(1), 152-161 http://dx.doi.org/10.1016/j.beth.2012.09.003

Sullivan, C. M., \& Cain, D. (2004). Ethical and safety when obtaining information from or about battered women for research purposes. Journal of Interpersonal Violence, 19(5), 603-618. http://dx.doi.org/10.1177/0886260504263249

World Health Organization (WHO, 2001). Putting women first: ethical and safety recommendations for research on domestic violence against women. Retirado em 2 de setembro de 2016 de http://www.who.int/gender/violence/womenfirtseng.pdf-

$\begin{array}{ll}\text { Historial do } & \text { artigo } \\ \text { Recebido } & 21 / 09 / 2016 \\ \text { Aceite } & 12 / 04 / 2017 \\ \text { Publicado } & 07 / 2017\end{array}$


Considerações éticas na investigação com vítimas 